Check for updates

Cite this: RSC Adv., 2017, 7, 38773

Received 20th June 2017

Accepted 2nd August 2017

DOI: $10.1039 / c 7 r a 06879 d$

rsc.li/rsc-advances

\title{
Structural optimization of large acceptor-donor- acceptor-type molecules for improved performance of fullerene-free polymer solar cells $\uparrow$
}

\begin{abstract}
Min Ju Cho, \$ Gi Eun Park, \$ Seo Yeon Park, Young-Un Kim and Dong Hoon Choi (DD *
To control the molecular energy levels of highly $\pi$-extended $n$-type molecules, we synthesized two acceptordonor-acceptor (A-D-A)-type molecules with indacenodithiophenes (IDTs) or IDT-benzodithiophene (BDT)IDT as donating cores and 2-(2,3-dihydro-3-oxo- $1 \mathrm{H}$-inden-1-ylidene)propanedinitrile (IM) as terminal accepting units. These molecules showed different optical and electrochemical properties, indicating that the energy levels can be easily tuned by changing the structure of the donating core. Among two molecules, IM-BDTIDT2 showed a relatively blue shifted absorption spectrum and low-lying highest occupied molecular orbital (HOMO) and lowest unoccupied molecular orbital (LUMO) levels. Although IMIDT3 and IM-BDTIDT2 have a highly $\pi$-extended conjugated structure, no clear crystalline behaviour was observed in their thin films. When applied to polymer solar cells (PSCs), the device based on IM-BDTIDT2 displayed a higher PCE (5.33\%) than the device bearing IM-IDT3 owing to the lower-lying energy levels of IM-BDTIDT2. Thus, the use of BDT as a donating core unit is favorable for limiting high-lying energy levels in highly $\pi$-extended A-D-A-type molecules.
\end{abstract}

\section{Introduction}

To obtain high power conversion efficiency (PCE) in nonfullerene-based bulk heterojunction (BHJ) polymer solar cells (PSCs), many kinds of n-type semiconducting organic molecules have been developed recently. ${ }^{1-6}$ Although fullerene derivatives such as [6,6]-phenyl- $\mathrm{C}_{61} / \mathrm{C}_{71}$-butyric acid methyl ester $\left(\mathrm{PC}_{61} \mathrm{BM}\right.$ and $\mathrm{PC}_{71} \mathrm{BM}$ ) have good n-type semiconducting properties and display outstanding PSC performance, they suffer from high costs and limitations in light absorption range, energy levels, and internal morphology control in blend films. ${ }^{7-13}$

Recently, it has been suggested that an efficient design strategy for non-fullerene acceptors is to combine a typical conjugated donor core with acceptor units such as perylene diimide (PDI), rhodanine, and dicyanovinyl; the resultant molecules are denoted as acceptor-donor-acceptor (A-D-A)-type molecules. ${ }^{14-22}$ The PCE values of $\mathrm{BHJ}$ PSCs based on such n-type molecules have been rapidly improved through the development of device architectures and appropriate p-type D-A copolymers to replace polythiophene derivatives which are donor-only polymers. ${ }^{23-27}$

Among the various n-type organic semiconductors, dicyanovinyl-based electron withdrawing groups have attracted considerable attention because their combination with various

Department of Chemistry, Research Institute for Natural Sciences, Korea University, 5 Anam-dong, Sungbuk-gu, Seoul 136-701, Korea.E-mail: dhchoi8803@korea.ac.kr

$\dagger$ Electronic supplementary information (ESI) available: MALDI-TOF, device performance, GI-XRD. See DOI: 10.1039/c7ra06879d

\$ These authors contributed equally. building blocks can result in facile tunability of energy levels and absorption properties for specific A-D-A molecules. Additionally, it was found that the molar absorption efficiencies of such molecules, from the visible to near infrared (NIR) region, are much larger than those of fullerene derivatives.

For example, a new series of n-type semiconducting molecules consisting of indacenodithiophene (IDT) or indacenodithienothiophene derivatives as donor cores and 2-(2,3-dihydro-3-oxo- $1 \mathrm{H}$ inden-1-ylidene)propanedinitrile (IM) as terminal acceptor groups in A-D-A-type molecules have been demonstrated to show high PCE values in non-fullerene-based BHJ PSCs. ${ }^{28-36}$ Advantageously, the energy levels of these molecules were also easily tuned by introducing thienothiophene or thiophene bridges. On the other hand, size variation of the donating core unit in A-D-A-type molecules has been studied less frequently. Such variation is an important design strategy for governing molecular energy levels, improving film-forming properties, and controlling morphologies in donor-acceptor blend films.

In this work, we designed and synthesized highly $\pi$-extended n-type semiconducting molecules with IDT-IDT-IDT core or an IDT-benzodithiophene (BDT)-IDT core as donating units and IM as terminal accepting units, as shown in Fig. 1. IM-IDT3 was reported to show poor PCE of 1.05\% in PSC device (PTB7-Th : IMIDT3) due to similar energy level of a PTB7-Th as p-type polymer. ${ }^{37}$

As a new n-type molecule, IM-BDTIDT2 was prepared to modify the energy levels of IM-IDT3. These n-type semiconducting molecules showed relatively high-lying highest occupied molecular orbital (HOMO) and lowest unoccupied molecular orbital (LUMO) energy levels compared with those of 

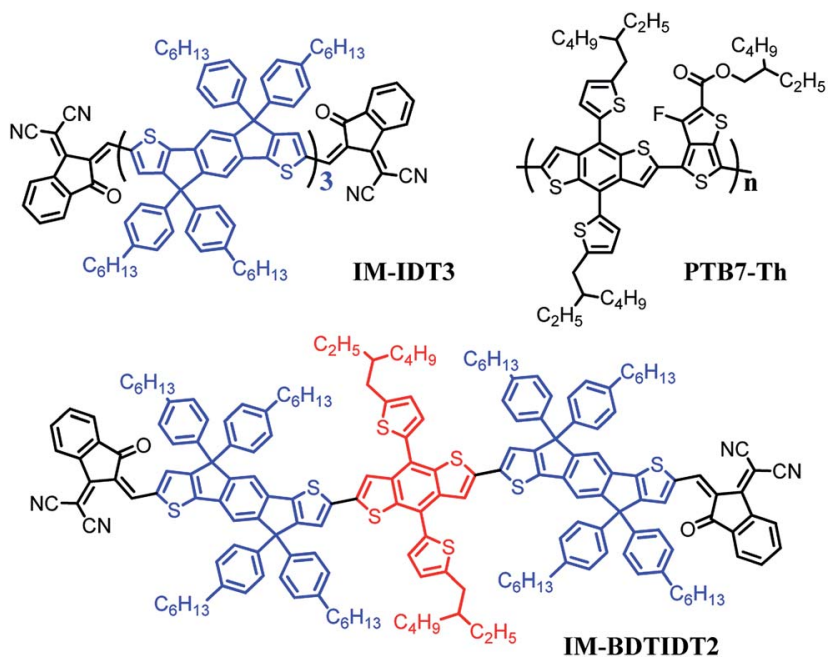

Fig. 1 Molecular structures of the n-type large molecules and p-type polymer PTB7-Th.

PCBM derivatives. Interestingly, IM-BDTIDT achieves favourable energy levels in PSCs which are lower-lying than those of IM-IDT3. Pure and blends films of IM-IDT3 and IM-BDTIDT2 showed lower degree of crystallinity or amorphous natures. A high PCE of $5.33 \%$ was achieved for PTB7-Th : IM-BDTIDT2based inverted BHJ solar cells, whereas the IM-IDT3-based devices showed PCE values of $3.25 \%$.

\section{Results and discussion}

\section{Synthesis and characterization}

The synthetic procedure for the final n-type semiconductor IMBDTIDT2, is shown in Scheme 1. IM-IDT3 was prepared according to literature. ${ }^{37}$ Compounds 3 bearing two aldehyde groups were prepared via Stille coupling reaction with compound $\mathbf{1}$ and compound 2. Finally, IM-BDTIDT2 was successfully synthesized quantitatively via typical Knoevenagel condensation reactions using the dialdehyde compound 3 and 2-(3-oxo-2,3-dihydro-1 $H$-inden-1-ylidene)malononitrile. To confirm the structures of the compounds synthesized herein, NMR and MALDI-TOF analyses were performed. Two final compounds were found to have good solubility in organic solvents, such as dichloromethane, THF, chloroform, and chlorinated benzenes.

\section{Optical and electrochemical properties}

UV-vis absorption spectra of the two synthesized n-type semiconducting molecules, IM-IDT3 and IM-BDTIDT2 were obtained in both solution and thin films. The corresponding spectra and parameters are displayed in Fig. 2 and Table 1. Two synthesized compounds show a strong NIR absorption band owing to strong intramolecular charge transfer (ICT) between IDT3 or BDTIDT2 as an electron-donating group and IMs as strong electron-withdrawing groups.

The wavelength of maximum absorbance $\left(\lambda_{\max }\right)$ of IM-IDT3 and IM-BDTIDT2 are 687 and $665 \mathrm{~nm}$, respectively, in chloroform solution and 707 and $671 \mathrm{~nm}$, respectively, in thin films. Although IM-BDTIDT2 has a highly $\pi$-extended backbone, similar to IM-IDT3, the absorption spectrum of IM-BDTIDT2 in solution shows a blue shift relative to that of IM-IDT3. Thus, it seems that the electron-donating ability of the BDT unit might be weaker than that of IDT.

Compared with those of IM-IDT3, the absorption spectrum of the IM-BDTIDT2 film shows relatively smaller bathochromic shift. This observation indicates that the IDT-BDT-IDT core in IM-BDTIDT2 might suppress intermolecular interactions (Fig. S3 $\dagger$ ). Additionally, molar extinction coefficient of IMBDTIDT2 is $2.04 \times 10^{5} \mathrm{M}^{-1} \mathrm{~cm}^{-1}$, which is relatively higher than that of IM-IDT3 as shown in Fig. S4a. $\dagger$ The optical bandgaps of IM-IDT3 and IM-BDTIDT2 calculated from the absorption edges in the absorption spectra of the thin films were 1.53 and $1.64 \mathrm{eV}$, respectively.
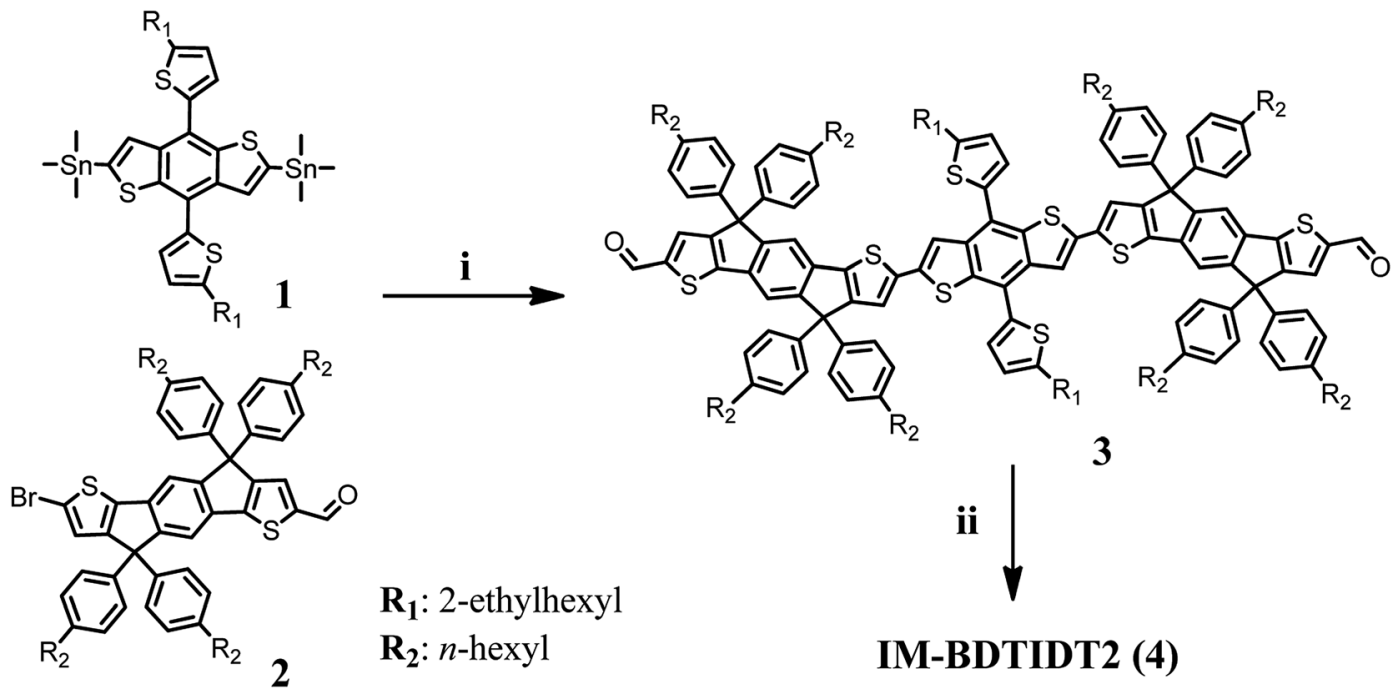

IM-BDTIDT2 (4)

Scheme 1 Synthetic procedure for IM-BDTIDT2: (i) $\mathrm{Pd}_{2}(\mathrm{dba})_{3}, \mathrm{P}(\mathrm{o} \text {-tolyl) })_{3}$, toluene, $100{ }^{\circ} \mathrm{C}, 12 \mathrm{~h}$. (ii) 2-(3-oxo-2,3-Dihydro-1H-inden-1-ylidene) malononitrile, ammonium acetate, chloroform, $70{ }^{\circ} \mathrm{C}, 5 \mathrm{~h}$. 
(a)

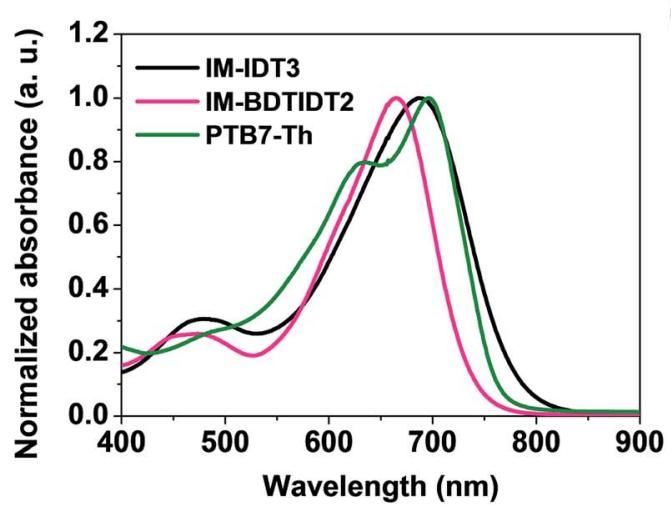

(c)

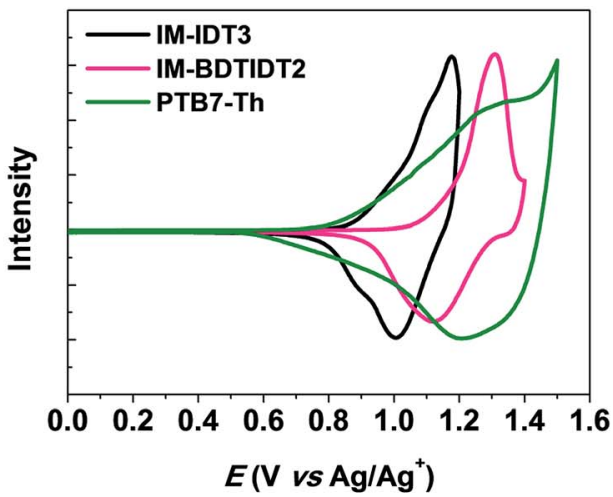

(b)

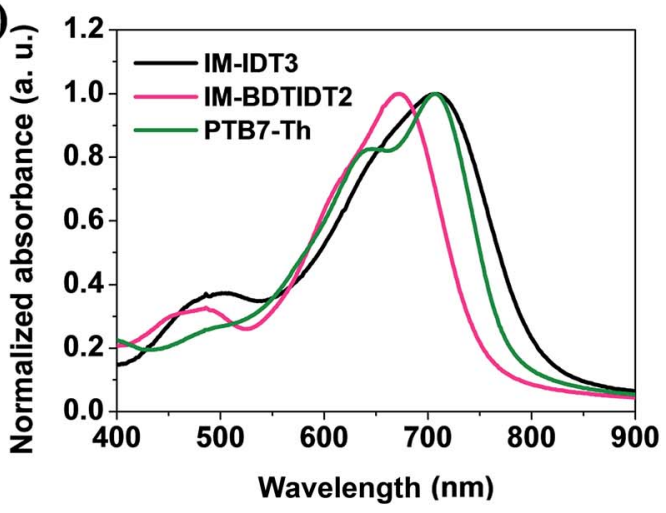

(d)

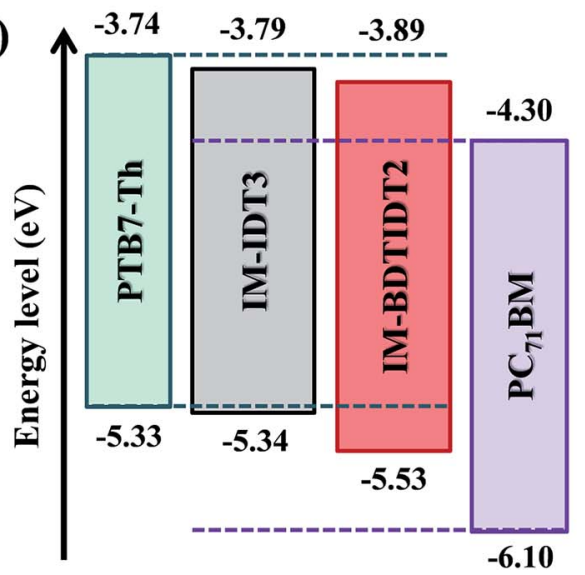

Fig. 2 UV-vis absorption spectra of IM-IDT3, IM-BDTIDT2, and PTB7-Th in solution (a) and in thin films (b). Cyclic voltammograms (c) and energy level diagram (d) of IM-IDT3, IM-BDTIDT2, PTB7-Th, and PC ${ }_{71} B M$.

Table 1 Summary of optical and electrochemical properties of IM-IDT3 and IM-BDTIDT2

\begin{tabular}{|c|c|c|c|c|c|c|c|}
\hline n-Type molecule & \multicolumn{2}{|c|}{ Absorption (nm) } & $\lambda_{\text {cut-off }}(\mathrm{nm})$ & $E_{\mathrm{g}}^{\mathrm{opt} b}(\mathrm{eV})$ & $E_{\mathrm{ox}}{ }^{c}(\mathrm{~V})$ & \multicolumn{2}{|c|}{ Energy level (eV) } \\
\hline IM-BDTIDT2 & $665(2.04)$ & 671 & 756 & 1.64 & 1.08 & -5.53 & -3.89 \\
\hline
\end{tabular}

${ }^{a} \varepsilon$ is a molar extinction coefficient $\left(\times 10^{-5} \mathrm{M}^{-1} \mathrm{~cm}^{-1}\right) .{ }^{b}$ Optical bandgap was obtained from the onset wavelength $\left(\lambda_{\text {cut-off }}\right)$ of the film. ${ }^{c}$ Values obtained from cyclic voltammograms. ${ }^{d}$ LUMO $(\mathrm{eV})=\mathrm{HOMO}(\mathrm{eV})+E_{\mathrm{g}}^{\mathrm{opt}}(\mathrm{eV})$.

The redox potentials of synthesized IM-IDT3 and IM-BDTIDT2 were examined using CV measurements, as shown in Fig. 2c. The oxidation potentials $\left(E_{\text {ox }}\right)$ of IM-IDT3 and IM-BDTIDT2 were 0.89 and $1.08 \mathrm{~V}$, respectively, and the corresponding HOMO levels were located at -5.34 and $-5.53 \mathrm{eV}$, respectively. The LUMO levels, as calculated from the HOMO levels and the optical bandgaps, were located at -3.81 and $-3.89 \mathrm{eV}$ for IM-IDT3 and IM-BDTIDT2, respectively. Compared with $\mathrm{PC}_{71} \mathrm{BM}$ derivatives, the LUMO levels of the synthesized molecules as acceptors are suitable for fabricating BHJ PSCs, as shown in Fig. 2d. It could lead us to expect a higher open circuit voltage $\left(V_{\text {oc }}\right)$ value in a PSC with the blend film containing PTB7-Th as p-type polymer.

However, as the energy levels of IM-IDT3 are very similar to those of PTB7-Th, (Fig. 2d), efficient charge separation and transport might not be achieved in an IM-IDT3 and PTB7-Th interface. Interestingly, the energy levels of IM-BDTIDT2 are slightly lower lying than those of IM-IDT3 owing to the effect of the BDT core.

\section{Performance of bulk heterojunction polymer solar cells}

BHJ PSCs were fabricated using the synthesized n-type molecules and PTB7-Th as a well-known p-type semiconducting polymer. We chose an inverted solar cell structure with the configuration of ITO/ZnO/PTB7-Th : n-type molecule/ $\mathrm{MoO}_{3} / \mathrm{Ag}$. To obtain the best device performance, the donor and acceptor blend ratio and the amount of DPE as a solvent additive were optimized, as shown in Table S1.† 
(a)

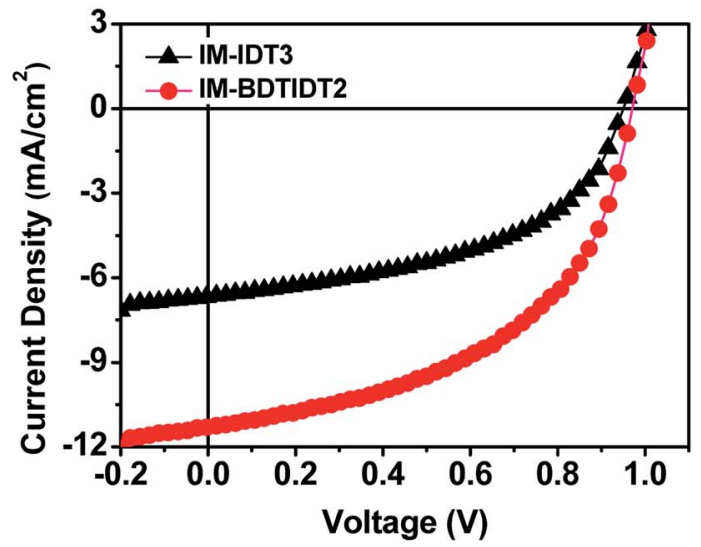

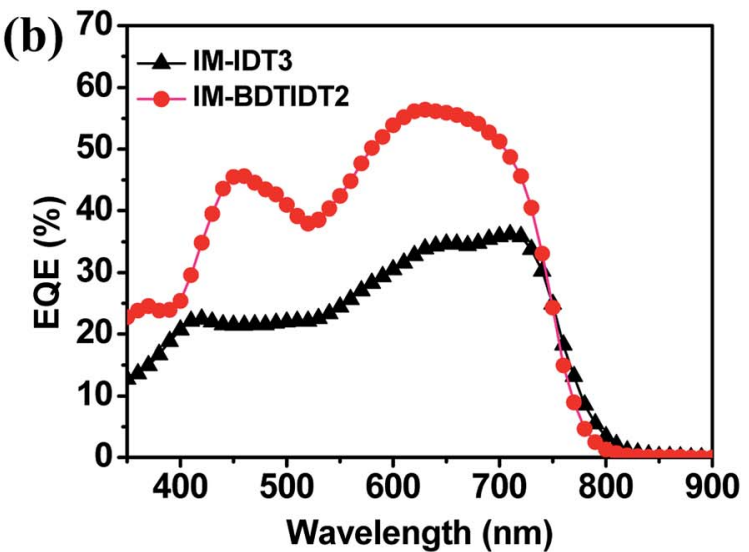

Fig. 3 J-V curves (a) and EQE spectra (b) of PTB7-Th : IM-IDT3 (1 : 1) with 4 vol\% DPE, and PTB7-Th : IM-BDTIDT2 (1 : 1) with 2 vol\% DPE.

Table 2 Parameters of PSCs based on IM-IDT3 and IM-BDTIDT2 measured at $100 \mathrm{~mW} \mathrm{~cm} \mathrm{~cm}^{-2}$ AM 1.5 illumination

\begin{tabular}{lllllll}
\hline n-Type molecule & D/A ratio $(\mathrm{wt} \%)$ & Solvent/additive & $V_{\text {oc }}(\mathrm{V})$ & $J_{\text {sc }}\left(\mathrm{mA} \mathrm{cm}^{-2}\right)$ & FF $(\%)$ & PCE ${ }^{a}(\%)$ \\
\hline IM-IDT3 & $1: 1$ & CB & $0.95(0.94 \pm 0.01)$ & $5.72(5.68 \pm 0.04)$ & $49.87(49.63 \pm 0.24)$ & $2.70(2.65 \pm 0.05)$ \\
& $1: 1$ & CB/DPE $4 \%$ & $0.95(0.94 \pm 0.01)$ & $7.15(7.06 \pm 0.09)$ & $47.82(47.71 \pm 0.11)$ & $3.25(3.17 \pm 0.08)$ \\
IM-BDTIDT2 & $1: 1$ & CB & $0.96(0.95 \pm 0.01)$ & $9.42(8.97 \pm 0.45)$ & $50.79(50.67 \pm 0.12)$ & $4.57(4.32 \pm 0.25)$ \\
& $1: 1$ & CB/DPE $2 \%$ & $0.97(0.96 \pm 0.01)$ & $11.28(10.89 \pm 0.39)$ & $48.72(48.58 \pm 0.14)$ & $5.33(5.08 \pm 0.25)$
\end{tabular}

${ }^{a}$ Average PCE values, which were obtained from more than 10 devices, are shown in parentheses.

Fig. 3a and $\mathrm{b}$ show the current density-voltage $(J-V)$ and external quantum efficiency (EQE) characteristics of PTB7Th : n-type-molecule-based devices obtained under simulated AM $1.5 \mathrm{G}$ solar illumination at an intensity of $100 \mathrm{~mW} \mathrm{~cm}^{-2}$, and the resultant device performance parameters are summarized in Tables 2 and S1. $\uparrow$ The best PCE value for PTB7-Th : IM-IDT3 with a $1: 1(\mathrm{w} / \mathrm{w})$ blend ratio and 4 vol\% DPE additive was $3.25 \%$, which is three times higher than that of published PSCs made of an $o$-DCB solution of PTB7-Th : IM-IDT3 $(1: 1.5)$ blend without adding any additives. ${ }^{37}$ Interestingly, the PTB7-Th : IM-BDTIDT2 based device (1:1, 2 vol\% DPE additive) exhibited the highest PCE of $5.3 \%$. Interestingly, two devices showed the high $V_{\text {oc }}$ value from 0.96 to $0.97 \mathrm{~V}$, which is consistent with the difference between the LUMO level of the acceptor and the HOMO level of PTB7-Th obtained from the CV results. Compared to IM-IDT3, IMBDTIDT2-based device with $2 \%$ DPE exhibited high $J_{\text {sc }}$ value of $11.28 \mathrm{~mA} \mathrm{~cm}^{-2}$.

The EQE spectra of the corresponding devices are shown in Fig. 3b. EQE spectrum shapes of them correspond to the absorption band of their blend films, as shown in Fig. S5. $\dagger$ The IM-BDTIDT2-based devices with higher PCE values show high photon-to-current responses from 500 to $800 \mathrm{~nm}$, whereas the IM-IDT3-based device exhibit relatively low EQE values. This observation indicates that the PTB7-Th : IM-BDTIDT2 blend achieves more efficient photoelectron conversion.

Moreover as shown in Fig. S6 and Table S2, $\dagger$ the device fabricated with the PTB7-Th : IM-BDTIDT2 blend had a relatively low ratio of hole and electron mobility $\left(\mu_{\mathrm{h}} / \mu_{\mathrm{e}}=6.32\right)$ compared to that of PTB7-Th : IM-IDT3-based device $\left(\mu_{\mathrm{h}} / \mu_{\mathrm{e}}=\right.$
10.65). This result may explain the relatively high $J_{\mathrm{sc}}$ of the PTB7-Th : IM-BDTIDT2 BHJ device.

The microstructural features of the pure molecule films and their optimized blend films were investigated by twodimensional GIWAXS, as shown in Fig. 4, S7 and S8. $\dagger$ IMIDT3 and IM-BDTIDT2 showed poor crystallinity, both in pristine and PTB7-Th blend films. This behavior might be attributable to the longer length of these molecules and high
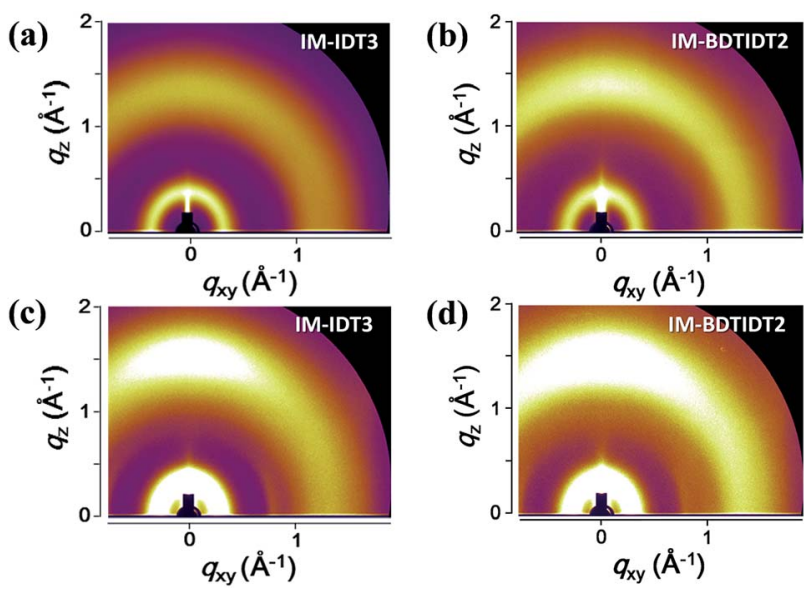

Fig. 4 Two-dimensional GIWAXS images of pure IM-IDT3 and IMBDTIDT2 films (a, b), and optimized PTB7-Th : IM-IDT3 and PTB7Th: IM-BDTIDT2 blend films (c, d): PTB7-Th : IM-IDT3 (1:1) with 4 vol\% DPE (c), and PTB7-Th : IM-BDTIDT2 (1: 1) with 2 vol\% DPE (d). 

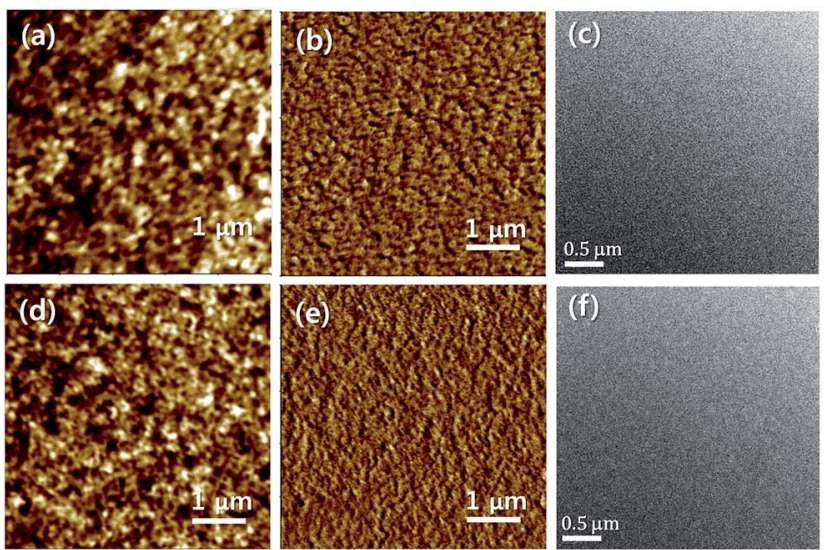

Fig. 5 AFM topography $(a, d)$, phase $(b, e)$ images $(5 \mu m \times 5 \mu m)$ and TEM images (c, f) of the blended films: (a-c) PTB7-Th : IM-IDT3 with 2 vol\% DPE, and (d-f) PTB7-Th : IM-BDTIDT2 with 2 vol\% DPE blend films.

rotational freedom in the structure of IDTs or IDT-BDT-IDT. From this result, we could not find significantly different crystalline behavior in pure and blend films.

To find other evidences of the PSC performance, the surface and internal morphologies of the optimized blend films were investigated by AFM and TEM, respectively. The IM-IDT3 and IM-BDTIDT2 films display very similar surface morphologies as shown in Fig. 5. Additionally, no clear phase segregation behaviors are observed in the blend films of PTB7-Th : IM-IDT3 and PTB7-Th : IM-BDTIDT2 as shown in TEM images (Fig. 5c and f). The formation of fine domains and the occurrence of nanophase separation are crucial factors for improving $J_{\text {sc }}$ values by achieving efficient exciton diffusion and increasing the interfacial area for efficient exciton dissociation between the $\mathrm{p}$ - and n-type molecules. However, although PTB7-Th : IM-IDT3 showed favorable morphology with a fine structure, the corresponding device exhibited relatively poor photovoltaic performance. It is probably that the different PSC performance observed for IM-IDT3- and IM-BDTIDT2-based devices could be governed by their molecular energy levels. ${ }^{38}$

\section{Conclusions}

To investigate the correlation between HOMO/LUMO energy levels and donating cores, we synthesized two different A-D-A-type large molecules containing the same or different donating cores. IM-IDT3 and IM-BDTIDT2 showed NIR absorption spectra and higher-lying HOMO and LUMO levels compared to those of PCBM. However, the energy levels of IM-IDT3 were very close to those of the p-type polymer PTB7-Th. In contrast, IM-BDTIDT2 with an IDT-BDT-IDT core exhibited a significantly blue-shifted absorption spectrum and lower-lying energy levels, which overcomes the disadvantages of IM-IDT3 bearing an IDT-IDT-IDT core. PTB7-Th : IM-BDTIDT2 exhibited significantly improved device performance compared with the IM-IDT3-based device owing to the fine surface and internal morphology of blend films and favorable energy levels.

\section{Experimental}

\section{Materials}

All starting reagents were purchased from Tokyo Chemical Industry, Sigma-Aldrich, and Acros Organics. The reagent-grade solvents used in this study were freshly dried using standard methods. Compounds 1, 2, and IM-IDT3 were synthesized according to literature methods. ${ }^{37,39}$

\section{Synthesis of compound 3}

$\mathrm{Pd}_{2}(\mathrm{dba})_{3}(11.4 \mathrm{mg}, 10.0 \mu \mathrm{mol})$ and $\mathrm{P}(o \text {-tolyl })_{3}(11.4 \mathrm{mg}, 10.0$ $\mu \mathrm{mol})$ were added to a solution of compound $1(0.09 \mathrm{~g}, 0.1$ $\mathrm{mmol}$ ) and compound $2(0.203 \mathrm{~g}, 0.2 \mathrm{mmol})$ in toluene $(20 \mathrm{~mL})$ at room temperature under an argon atmosphere. The mixture was heated to $100{ }^{\circ} \mathrm{C}$ and stirred at this temperature for $12 \mathrm{~h}$. After cooling the mixture to room temperature, the mixture was poured into water $(50 \mathrm{~mL})$ and then extracted with dichloromethane. The organic layer was dried over $\mathrm{MgSO}_{4}$ and the solvent was evaporated under reduced pressure. The resulting product was purified by silica gel column chromatography (methylene chloride : hexane $=1: 4)$ to yield $0.212 \mathrm{~g}(87 \%)$ of compound 3. ${ }^{1} \mathrm{H}$ NMR (500 MHz, $\mathrm{CDCl}_{3}$ ): $\delta(\mathrm{ppm}) 9.81(\mathrm{~s}, 2 \mathrm{H})$, $7.64(\mathrm{~s}, 2 \mathrm{H}), 7.62(\mathrm{~s}, 2 \mathrm{H}), 7.54(\mathrm{~s}, 2 \mathrm{H}), 7.41(\mathrm{~s}, 2 \mathrm{H}), 7.27(\mathrm{~d}, J=$ $4.5 \mathrm{~Hz}, 2 \mathrm{H}), 7.07-7.18(\mathrm{~m}, 34 \mathrm{H}), 6.91$ (d, $J=4.5 \mathrm{~Hz}, 2 \mathrm{H}), 2.88$ (d, $4 \mathrm{H}), 2.57(\mathrm{t}, 16 \mathrm{H}), 1.71(\mathrm{~m}, 2 \mathrm{H}), 1.59(\mathrm{~m}, 16 \mathrm{H}), 1.29-1.36(\mathrm{~m}$, $64 \mathrm{H}), 0.86-0.92(\mathrm{t}, 36 \mathrm{H}) .{ }^{13} \mathrm{C} \mathrm{NMR}\left(125 \mathrm{MHz}, \mathrm{CDCl}_{3}\right): \delta(\mathrm{ppm})$ $182.76,157.74,156.11,154.95,153.85,151.35,146.07,145.45$, 141.96, 141.83, 141.06, 140.91, 140.86, 138.61, 138.36, 137.32, $137.27,136.67,133.73,132.07,128.53,128.48,127.81,127.65$, $125.47,123.26,121.19,118.92,117.49,63.11,62.84,41.40$, $35.55,35.53,34.30,32.49$, 31.69, 31.30, 29.11, 29.08, 28.93, $25.77,23.04,22.57,14.21,14.07,10.91$. MALDI-TOF: $\mathrm{m} / \mathrm{z} 2442.49$ $\left[\mathrm{M}^{+}\right]$. Anal. calcd for $\mathrm{C}_{164} \mathrm{H}_{186} \mathrm{~N}_{4} \mathrm{O}_{2} \mathrm{~S}_{8}$ : C, 80.54; H, 7.67; S, 10.49. Found: C, 80.37; H, 7.61; S, 10.45\%.

\section{Synthesis of compound 4 (IM-BDTIDT2)}

IM-BDTIDT2 was synthesized via Knoevenagel condensation of compound 3 (0.20 g, $0.08 \mathrm{mmol})$ and 2-(3-oxo-2,3-dihydro- $1 \mathrm{H}$ inden-1-ylidene)malononitrile $(0.06 \mathrm{~g}, 0.32 \mathrm{mmol})$ with ammonium acetate as a catalyst. The mixture was heated at $70{ }^{\circ} \mathrm{C}$ for $5 \mathrm{~h}$. The resulting product was purified by silica gel column chromatography (methylene chloride : hexane $=1: 4$ ) to yield $0.181 \mathrm{~g}(81 \%)$ of IM-BDTIDT2 as a dark green solid. ${ }^{1} \mathrm{H}$ NMR $\left(500 \mathrm{MHz}, \mathrm{CDCl}_{3}\right): \delta(\mathrm{ppm}) 8.88(\mathrm{~s}, 2 \mathrm{H}), 8.68(\mathrm{~d}, J=7.5 \mathrm{~Hz}, 2 \mathrm{H})$, $7.88(\mathrm{~d}, J=7.5 \mathrm{~Hz}, 2 \mathrm{H}), 7.72(\mathrm{~m}, 4 \mathrm{H}), 7.69(\mathrm{~s}, 2 \mathrm{H}), 7.67(\mathrm{~s}, 2 \mathrm{H})$, $7.65(\mathrm{~s}, 2 \mathrm{H}), 7.42(\mathrm{~s}, 2 \mathrm{H}), 7.29$ (d, $J=4.5 \mathrm{~Hz}, 2 \mathrm{H}), 7.23(\mathrm{~s}, 2 \mathrm{H})$, 7.09-7.17 (m, 32H), $6.92(\mathrm{~d}, J=4.5 \mathrm{~Hz}, 2 \mathrm{H}), 2.88(\mathrm{~d}, 4 \mathrm{H}), 2.58(\mathrm{t}$, $16 \mathrm{H}), 1.71$ (m, 2H), 1.60 (m, 16H), 1.29-1.36 (m, 64H), 0.87-0.92 $(\mathrm{t}, 36 \mathrm{H}) .{ }^{13} \mathrm{C}$ NMR (125 MHz, $\left.\mathrm{CDCl}_{3}\right): \delta$ (ppm) 188.39, 160.79, 160.48 , 158.45, 157.09, 156.27, 154.22, 146.14, 142.10, 141.95, $141.90,140.92,140.63,140.40,139.91,139.60,138.89,138.70$, 138.52, 138.32, 137.30, 136.84, 136.58, 134.90, 134.24, 133.73, 128.62, 128.56, 127.81, 127.74, 127.70, 125.49, 125.18, 124.60, $123.57,123.35,121.57,119.77,119.10,117.53,114.77,68.41$, $63.08,62.84,41.40,35.55,35.53,34.30,32.50,31.68,31.28$, $29.07,28.93,25.77,23.04,22.55,14.20,14.07,10.91$. MALDI- 
TOF: $m / z 2794.09\left[\mathrm{M}^{+}\right]$. Anal. calcd for $\mathrm{C}_{188} \mathrm{H}_{194} \mathrm{~N}_{4} \mathrm{O}_{2} \mathrm{~S}_{8}$ : C, 80.70; H, 6.99; N, 2.00; S, 9.17. Found: C, 80.68; H, 6.92; N, 2.04; S, 9.13.

\section{Instrumentation}

${ }^{1} \mathrm{H}$ NMR spectra were acquired using a Varian Mercury a Bruker $500 \mathrm{MHz}$ spectrometer. Elemental analyses were performed using an EA1112 elemental analyzer to establish C, H, N, and S contents. The masses of the synthesized compounds were determined by matrix-assisted laser desorption ionization timeof-flight (MALDI-TOF) mass spectrometry (LRF20, Bruker Daltonics). Absorption spectra were recorded on a UV-vis absorption spectrophotometer (HP 8453, photodiode array). Cyclic voltammetry (CV) experiments were performed using an eDAQ EA161 potentiostat. The reference and counter electrodes were $\mathrm{Ag} / \mathrm{AgCl}$ and $\mathrm{Pt}$ wire $(0.5 \mathrm{~mm}$ in diameter $)$, respectively. The working electrodes were obtained by coating the prepared polymer films onto Pt plates. The electrolyte solution consisted of tetrabutylammonium hexafluorophosphate $\left(\mathrm{Bu}_{4} \mathrm{NPF}_{6}\right)$ $(0.1 \mathrm{M})$ in acetonitrile. The morphology of each polymer film surface was analyzed by atomic force microscopy (AFM; Advanced Scanning Probe Microscope, XE-100, PSIA). The internal morphologies of each polymer film and the film blends were investigated using transmission electron microscopy (TEM; Tecnai G2 F30, FEI Inc.) at an accelerating voltage of 300 $\mathrm{kV}$. GIWAXS measurements were carried out at the PLS-II 9A ultra-small-angle X-ray scattering beamline at the Pohang Accelerator Laboratory (energy $=11.04 \mathrm{keV}$, wavelength $(\lambda)=$ $\left.1.126 \AA, 2 \theta=0-20^{\circ}\right)$. The parameters $q_{x y}$ and $q_{z}$ represent the components of the scattering vectors parallel and perpendicular to the film surface, respectively.

\section{Fabrication of polymer solar cells}

$\mathrm{BHJ}$ PSCs were fabricated with an inverted device configuration (indium tin oxide (ITO)/ZnO/PTB7-Th : A-D-A/MoO $/ \mathrm{Ag}$ ). A thin layer of $\mathrm{ZnO}$ was fabricated on the surface of ITO-patterned glass, which was treated with UV-ozone for $20 \mathrm{~min}$. After annealing the $\mathrm{ZnO}$ layer thermally at $200{ }^{\circ} \mathrm{C}$ for $1 \mathrm{~h}$, the active layer was prepared on top of the $\mathrm{ZnO}$ layer by spin-coating the blended solution of PTB7-Th : A-D-A dissolved in chlorobenzene with or without diphenyl ether (DPE) as a solvent additive. Subsequently, the electrodes were subjected to thermal evaporation to form a $10 \mathrm{~nm} \mathrm{MoO}$ layer and a $100 \mathrm{~nm} \mathrm{Ag}$ layer (0.04 $\mathrm{cm}^{2}$ photoactive area). A Keithley 2400 source meter was used to investigate the current density-voltage $(J-V)$ characteristics in the dark and under AM $1.5 \mathrm{G}$ illumination at $100 \mathrm{~mW} \mathrm{~cm}^{-2}$, as supplied by a solar simulator (Oriel, 1000 W). An AM 1.5 filter (Oriel) and a neutral density filter were used to adjust the light intensity. The incident light intensity was measured with a calibrated broadband optical power meter (Spectra Physics, Model 404).

\section{Acknowledgements}

The authors acknowledge the financial support from the National Research Foundation of Korea (NRF2012R1A2A1A01008797) and from the Key Research
Institute Program (NRF20100020209). We are grateful to Pohang Accelerator Laboratory (Pohang, Korea) for allowing us to conduct the grazing incidence X-ray diffraction (GI-XRD) measurements.

\section{Notes and references}

1 W. Chen and Q. Zhang, J. Mater. Chem. C, 2017, 5, 1275.

2 S. M. McAfee, J. M. Topple, I. G. Hill and G. C. Welch, J. Mater. Chem. A, 2015, 3, 16393.

3 H. Li, T. Earmme, G. Ren, A. Saeki, S. Yoshikawa, N. M. Murari, S. Subramaniyan, M. J. Crane, S. Seki and S. A. Jenekhe, J. Am. Chem. Soc., 2014, 136, 14589.

4 O. K. Kwon, M. A. Uddin, J. H. Park, S. K. Park, T. L. Nguyen, H. Y. Woo and S. Y. Park, Adv. Mater., 2016, 28, 910.

5 K. Wang, Y. Firdaus, M. Babics, F. Cruciani, Q. Saleem, A. E. Labban, M. A. Alamoudi, T. Marszalek, W. Pisula, F. Laquai and P. M. Beaujuge, Chem. Mater., 2016, 28, 2200. 6 G. E. Park, S. Choi, D. H. Lee, M. Godumala, M. A. Uddin, H. Y. Woo, M. J. Cho and D. H. Choi, J. Mater. Chem. A, 2017, 5, 663.

7 J.-D. Chen, C. Cui, Y.-Q. Li, L. Zhou, Q.-D. Ou, C. Li, Y. Li and J.-X. Tang, Adv. Mater., 2015, 27, 1035.

8 B. Kan, M. Li, Q. Zhang, F. Liu, X. Wan, Y. Wang, W. Ni, G. Long, X. Yang, H. Feng, Y. Zuo, M. Zhang, F. Huang, Y. Cao, T. P. Russell and Y. Chen, J. Am. Chem. Soc., 2015, 137, 3886.

9 W. Zhao, D. Qian, S. Zhang, S. Li, O. Inganäs, F. Gao and J. Hou, Adv. Mater., 2016, 28, 4734.

10 Y.-J. Hwang, H. Li, B. A. E. Courtright, S. Subramaniyan and S. A. Jenekhe, Adv. Mater., 2016, 28, 124.

11 G. E. Park, S. Choi, J. Shin, M. J. Cho and D. H. Choi, Org. Electron., 2016, 34, 157.

12 D. Meng, D. Sun, C. Zhong, T. Liu, B. Fan, L. Huo, Y. Li, W. Jiang, H. Choi, T. Kim, J. Y. Kim, Y. Sun, Z. Wang and A. J. Heeger, J. Am. Chem. Soc., 2016, 138, 375.

13 Y. J. He and Y. F. Li, Phys. Chem. Chem. Phys., 2011, 13, 1970. 14 X. Zhang, C. L. Zhan and J. N. Yao, Chem. Mater., 2015, 27, 166.

15 S. Holliday, R. S. Ashraf, A. Wadsworth, D. Baran, S. A. Yousaf, C. B. Nielsen, C. H. Tan, S. D. Dimitrov, Z. R. Shang, N. Gasparini, M. Alamoudi, F. Laquai, C. J. Brabec, A. Salleo, J. R. Durrant and I. McCulloch, Nat. Commun., 2016, 7, 11585.

16 H. T. Bai, Y. Wu, Y. F. Wang, Y. Wu, R. Li, P. Y. Cheng, M. Y. Zhang, J. Y. Wang, W. Ma and X. W. Zhan, J. Mater. Chem. A, 2015, 3, 20758.

17 M. M. Li, Y. T. Liu, W. Ni, F. Liu, H. R. Feng, Y. M. Zhang, T. T. Liu, H. T. Zhang, X. J. Wan, B. Kan, Q. Zhang, T. P. Russell and Y. S. Chen, J. Mater. Chem. A, 2016, 4, 10409. 18 K. E. Yi, G. E. Park, J. H. Lee, H. J. Kim, D. H. Lee, H. Ahn, M. A. Uddin, H. Y. Woo, M. J. Cho and D. H. Choi, ACS Appl. Mater. Interfaces, 2017, 9, 8838.

19 Y. Lin and X. Zhan, Mater. Horiz., 2014, 1, 470.

20 Y. Lin and X. Zhan, Acc. Chem. Res., 2016, 49, 175.

21 P. Cheng, M. Zhang, T.-K. Lau, Y. Wu, B. Jia, J. Wang, C. Yan, M. Qin, X. Lu and X. Zhan, Adv. Mater., 2017, 29, 1605216. 
22 W. Wang, C. Yan, T.-K. Lau, J. Wang, K. Liu, Y. Fan, X. Lu and X. Zhan, Adv. Mater., 2017, DOI: 10.1002/adma.201701308.

23 Y. Qin, M. A. Uddin, Y. Chen, B. Jang, K. Zhao, Z. Zheng, R. Yu, T. J. Shin, H. Y. Woo and J. Hou, Adv. Mater., 2016, 28, 9416.

24 H. Bin, L. Gao, Y. Yang, Y. Zhang, C. Zhang, S. Chen, L. Xue, C. Yang, M. Xiao and Y. Li, Nat. Commun., 2016, 7, 13651.

25 G. E. Park, H. J. Kim, S. Choi, D. H. Lee, M. A. Uddin, H. Y. Woo, M. J. Cho and D. H. Choi, Chem. Commun., 2016, 52, 8873.

26 J. Yuan, L. Qiu, Z.-G. Zhang, Y. Li, Y. Chen and Y. Zou, Nano Energy, 2016, 30, 312.

27 D. Liu, B. Yang, B. Jang, B. Xu, S. Zhang, C. He, H. Y. Woo and J. Hou, Energy Environ. Sci., 2017, 10, 546.

28 Y. Z. Lin, Z. G. Zhang, H. Bai, J. Wang, Y. Yao, Y. Li, D. Zhu and X. Zhan, Energy Environ. Sci., 2015, 8, 610.

29 Y. Lin, J. Wang, Z. Zhang, H. Bai, Y. Li, D. Zhu and X. Zhan, Adv. Mater., 2015, 27, 1170.

30 L. Gao, Z. G. Zhang, H. Bin, L. Xue, Y. Yang, C. Wang, F. Liu, T. P. Russell and Y. Li, Adv. Mater., 2016, 28, 8288.

31 H. Bin, Z.-G. Zhang, L. Gao, S. Chen, L. Zhong, L. Xue, C. Yang and Y. Li, J. Am. Chem. Soc., 2016, 138, 4657.
32 Y. Lin, F. Zhao, Q. He, L. Huo, Y. Wu, T. C. Parker, W. Ma, Y. Sun, C. Wang, D. Zhu, A. J. Heeger, S. R. Marder and X. Zhan, J. Am. Chem. Soc., 2016, 138, 4955.

33 Y. Lin, Q. He, F. Zhao, L. Huo, J. Mai, X. Lu, C. J. Su, T. Li, J. Wang, J. Zhu, Y. Sun, C. Wang and X. Zhan, J. Am. Chem. Soc., 2016, 138, 2973.

34 S. Dai, F. Zhao, Q. Zhang, T. Lau, T. Li, K. Liu, Q. Ling, C. Wang, X. Lu, W. You and X. Zhan, J. Am. Chem. Soc., 2017, 139, 1336.

35 F. Zhao, S. Dai, Y. Wu, Q. Zhang, J. Wang, L. Jiang, Q. Ling, Z. Wei, W. Ma, W. You, C. Wang and X. Zhan, Adv. Mater., 2017, 29, 1700144.

36 Y. Lin, F. Zhao, Y. Wu, K. Chen, Y. Xia, G. Li, S. K. K. Prasad, J. Zhu, L. Huo, H. Bin, Z.-G. Zhang, X. Guo, M. Zhang, Y. Sun, F. Gao, Z. Wei, W. Ma, C. Wang, J. Hodgkiss, Z. Bo, O. Inganas, Y. Li and X. Zhan, Adv. Mater., 2017, 29, 1604155.

37 Y. Lin, T. Li, F. Zhao, L. Han, Z. Wang, Y. Wu, Q. He, J. Wang, L. Huo, Y. Sun, C. Wang, W. Ma and X. Zhan, Adv. Energy Mater., 2016, 6, 1600854.

38 D. Veldman, S. C. J. Meskers and R. A. J. Janssen, Adv. Funct. Mater., 2009, 19, 1939.

39 J. Y. Kim, Y. U. Kim, H. J. Kim, H. A. Um, J. Shin, M. J. Cho and D. H. Choi, Macromol. Res., 2016, 24, 980. 